\title{
Intraocular pressure in postmenopausal Nigerian women with and without systemic hypertension
}

\section{JA Ebeigbea, PN Ebeigbeb and ADA Ighorojec}

a Department of Optometry, Faculty of Life Sciences, University of Benin, Nigeria

b Department of Obstetrics and Gynaecology, Faculty of Health Sciences, Delta State University,

Nigeria

c Department of Physiology, School of Basic Medical Sciences, University of Benin, Nigeria

$<$ jenniferebeigbe@yahoo.com>

Received 8 January 2011; revised version accepted 15 August 2011

\section{Abstract}

Background: Mean intraocular pressure (IOP) in postmenopausal women has been reported higher than that in menstruating women. Also, intraocular pressure is said to be positively correlated with systemic blood pressure. No previous study in Nigeria has compared intraocular pressure in postmenopausal women with and without systemic hypertension. Purpose: To investigate the effects of menopause on intraocular pressure in subjects with and without high blood pressure. Methods: Normotensive and hypertensive premenopausal and postmenopausal subjects in the same age range of 45 to 55 years were studied. Intraocular pressure was measured with the hand-held Kowa applanation tonometer. Blood pressure was taken in the sitting position at the right upper arm using a manual mercury sphygmomanometer with the right cuff size. The average of two readings was recorded. Results: Mean IOP for premenopausal nor- motensive women was $14.58 \pm 2.56 \mathrm{mmHg}$ while that of postmenopausal normotensive women was $16.15 \pm 1.80 \mathrm{mmHg}(p<0.05)$. Also, the difference in mean IOP between premenopausal hypertensive $(16.58 \pm 3.23 \mathrm{mmHg})$ and postmenopausal hypertensive women $(18.24 \pm 3.89 \mathrm{mmHg})$ was statistically significant $(p<0.05)$. A statistically significant and positive correlation was observed between IOP and systemic blood pressure in postmenopausal hypertensive women, $p<0.05$. Conclusion: Menopause significantly increases intraocular pressure. Mean intraocular pressure of hypertensive postmenopausal women was significantly higher than that of normotensive postmenopausal women, $(p<0.05)$. Knowledge of the normal level of intraocular pressure during various stages of the female reproductive cycle may help during glaucoma screening. (S Afr Optom 2011 70(3) 117-122)

Key words: Menopause, intraocular pressure, systemic blood pressure.

\section{Introduction}

Menopause is the point in a female's life when she has not had a menstrual cycle for at least one year. Menopause is not a disease or an illness but a transition between two phases of a woman's life. It marks the end of the childbearing years of the female. For most women menopause occurs at about age 50 but every woman's body has its own timeline. This would explain that while some women stop having their periods in their mid-forties others continue well into their fifties $^{1-3}$. At the time of menopause a woman must readjust her life from one that has been physiologically stimulated by estrogen and progesterone production 
to one devoid of these hormones. The loss of estrogen often causes marked physiologic changes in the function of the body and the eye is no exception ${ }^{4-8}$.

The influence of sex hormones on IOP has been the focus of some studies ${ }^{9-11}$. The ovaries are the primary source of protective estrogen in women of reproductive age. During menopause, a changing hormone profile in the body causes important shifts in the levels of estrogen present in the female body. Overall, this change is primarily a large drop in the average amount of circulating estrogen. The falling level of estrogen is the primary cause of familiar menopause symptoms such as hot flushes, mood swings, and appetite changes. As levels of estrogen decrease, a woman's risk of developing high blood pressure increases dramatically. Due to the interplay of other hormones and the effect that estrogen has on other important risk factors, post-menopausal women are actually at higher risk for developing high blood pressure than are men ${ }^{1,9}$. Investigations to determine the effect of menopause on visual function, cardiovascular and ocular hemodynamics showed that menopausal women had significantly higher IOP in both eyes as compared to premenopausal women ${ }^{12,13}$. Other studies $^{14-16}$ have reported a positive correlation between Intraocular pressure and systemic blood pressure.

The link between high blood pressure and menopause is complicated. While there is great indication that blood pressure increases with menopause, there is not a clear understanding of why this happens. There are many factors that are being considered such as age, and weight gain which happen as women get older. However, recent studies ${ }^{15-17}$ suggests that declining estrogen levels may be the main contributing factor for elevated blood pressure in menopausal women. The increase in eye pressure is a typical age-related phenomenon which may also be the result of an oestrogen deficiency. As an example, pre-menopausal women tend to have lower diastolic, and systolic pressure than men, but as women go into menopause, their systolic pressure increases to become slightly higher than that of men. The most common type of glaucoma is primary (open-angle) glaucoma, which occurs in approximately $4 \%$ of people aged over 50 years, with a higher frequency in women than in men ${ }^{17-19}$. The diagnosis of glaucoma is usually performed at the onset of presbyopia, when people mostly report to the clinic for the first time for eye check. It is also about this age that the majority of menopausal symptoms occur. This leads to the question as to whether there is a relationship between intraocular pressure and a reduction in oestrogen and progesterone in postmenopausal women ${ }^{20}$.

\section{Methods}

This was a cross-sectional study and thirty-three normotensive post menopausal women and 33 hypertensive postmenopausal women aged between 45-55 years old (mean age 51.09 \pm 2.34 and $52.30 \pm 1.52$ respectively) were recruited. Premenopausal women between the ages of 45-55 were also recruited into the study to act as controls. There were 33 normotensive premenopausal women (mean age $51.33 \pm 0.48$ ) and 33 hypertensive premenopausal women (mean age $51.73 \pm 1.56)$. A short medical history from the women revealed they were not on any medication for other systemic or ocular diseases.

Informed consent was obtained from the women and ethical approval for the study was obtained from the University of Benin Ethics Committee. The women recruited were members of staff of the University community, primary and secondary school teachers and members of neighbouring local churches. Blood pressure was measured with a manual mercury sphygmomanometer in a sitting position at the right upper arm using the right cuff size. Two readings were taken and the average recorded. Monocular direct ophthalmoscopy was done to rule out any diseases of the posterior segment. Intraocular pressure was measured with the handheld Kowa applanation tonometer. The eyes were anaesthetized with $0.5 \%$. Proparacaine and fluorescein strips, impregnated with $1 \mathrm{mg}$ of sodium, were used to stain the eyes. The average of two readings was recorded per subjects. The test was carried out between 12 noon and $2 \mathrm{pm}$ each time to avoid diurnal variation. The values used were for the right eyes only.

The data obtained was analyzed with SPSS version 15.0 (SPSS, Inc, Chicago, IL, USA).

\section{Results}

There was a statistically significant difference in mean intraocular pressure between the postmenopausal normotensive and postmenopausal hypertensive 
women, $p<0.05$. There was also a significant difference in IOP between premenopausal normotensive and the postmenopausal normotensive $(p<0.05)$, indicating the influence of menopause on intraocular pressure (see Table 1 and Figure 1)

Table 1: IOP and systemic blood pressure in premenopausal and postmenopausal women

\begin{tabular}{|c|c|c|c|c|c|}
\hline $\begin{array}{l}\text { Groups } \\
(\mathrm{N}=33)\end{array}$ & Mean Age \pm SD & $\begin{array}{l}\text { Mean } \\
\operatorname{IOP}(m m H g) \pm \\
\text { SD) }\end{array}$ & $\begin{array}{l}\text { Mean } \\
\text { Systolic } \\
\text { BP(mmHg) } \\
\text { SD }\end{array}$ & $\begin{array}{l}\text { Mean } \\
\text { Diastolic } \\
\text { BP(mmHg) } \\
\pm \mathrm{SD}\end{array}$ & $\begin{array}{l}95 \% \\
\text { confidence } \\
\text { interval }\end{array}$ \\
\hline $\begin{array}{l}\text { Normotensive } \\
\text { (Pre) }\end{array}$ & 51.33:0.48 & $14.58: 2.56$ & $132.03 \div 3,32$ & $82.94: 2.91$ & $13.66-15,48$ \\
\hline $\begin{array}{l}\text { Normotensive } \\
\text { (Post) }\end{array}$ & $51.09 \div 2.34$ & $16.15 \div 1.90$ & $136.09 \div 1.94$ & $85.73 \pm 2.63$ & $15.51 \cdot 16.79$ \\
\hline $\begin{array}{l}\text { Hypertensive } \\
\text { (Pre) }\end{array}$ & $51.73 \div 1.56$ & $16.58+3.23$ & $140.12 \pm 4.06$ & $89.39 \div 3.32$ & $15.43-17.72$ \\
\hline $\begin{array}{l}\text { Hypertensive } \\
\text { (Post) }\end{array}$ & $52.30=1.52$ & $18.24+3.89$ & $136.82 \pm .13 .82$ & $94.48 \pm 6.98$ & $19.86-22.62$ \\
\hline
\end{tabular}

Key: $\mathrm{SD}=$ Standard Deviation, $\mathrm{N}=$ Number of subjects, Pre $=$ Premenpausal and Post $=$ Postmenopausal

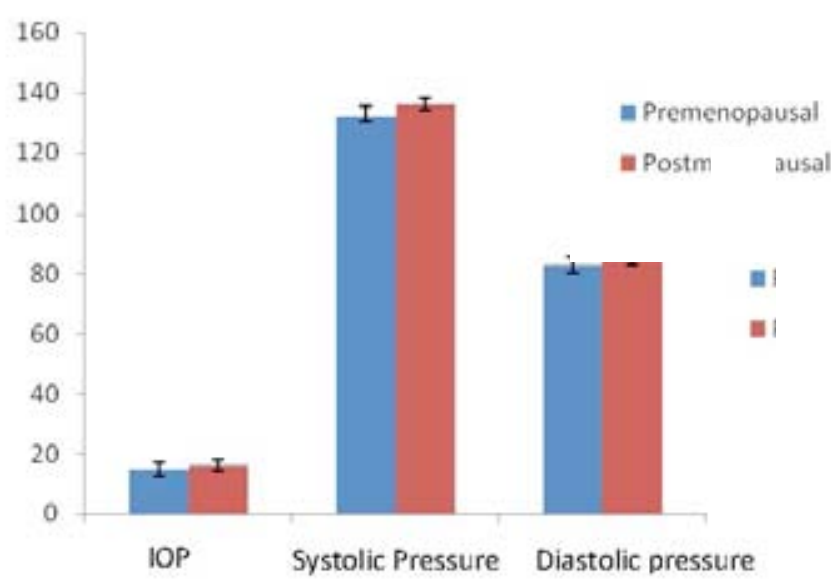

Figure 1: Mean IOP and BP for premenopausal and postmenopausal Normotensives

Mean IOP for premenopausal normotensive women was $14.58 \pm 2.56 \mathrm{mmHg}$ while that of postmenopausal normotensive women was $16.15 \pm 1.80 \mathrm{mmHg}$. $(p<0.05)$. Also, the difference in mean IOP between premenopausal hypertensive $(16.58 \pm 3.23 \mathrm{mmHg})$ and postmenopausal hypertensive women (18.24 \pm $3.89 \mathrm{mmHg})$ was statistically significant $(p<0.05)$.
Mean blood pressure was higher in the postmenopausal women than the premenopausal women. (Figure 2)

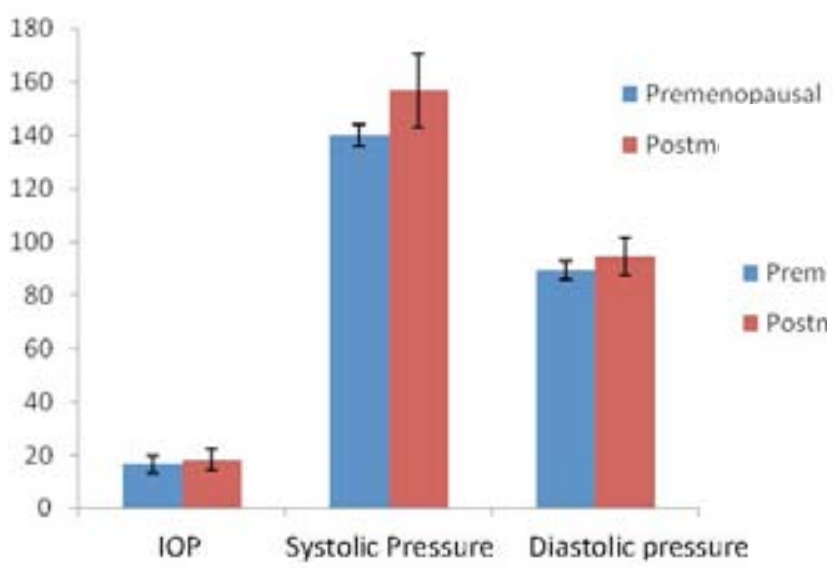

Figure 2: Mean IOP and BP for premenopausal and postmenopausal hypertensives

A statistically significant positive correlation was observed between IOP and systemic blood pressure in postmenopausal hypertensive women, $p<0.05$, (Figures 3 and 4). A highly significant positive correlation was also observed between IOP and systolic blood pressure in the premenopausal hypertensive women, Figure $5(r=0.60, p<0.05)$. Other correlations, however, were close to or almost zero and thus figures have not been included for these situations.

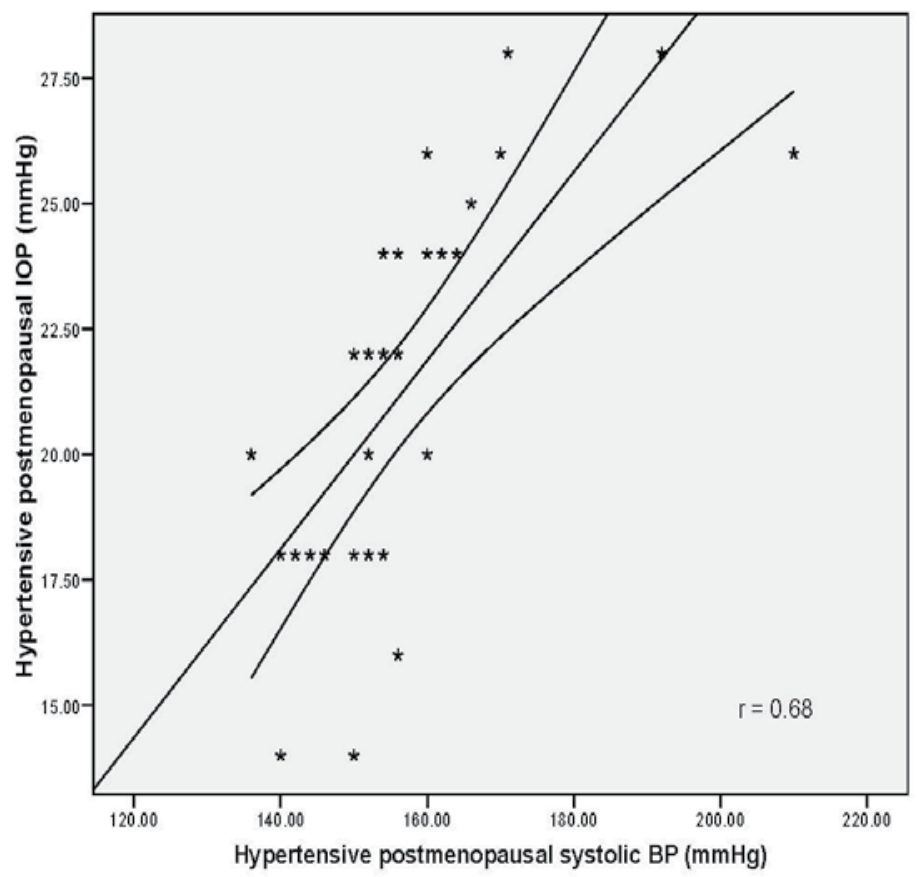

Figure 3: Positive correlation of IOP and systolic blood pressure in hypertensive postmenopausal women. 


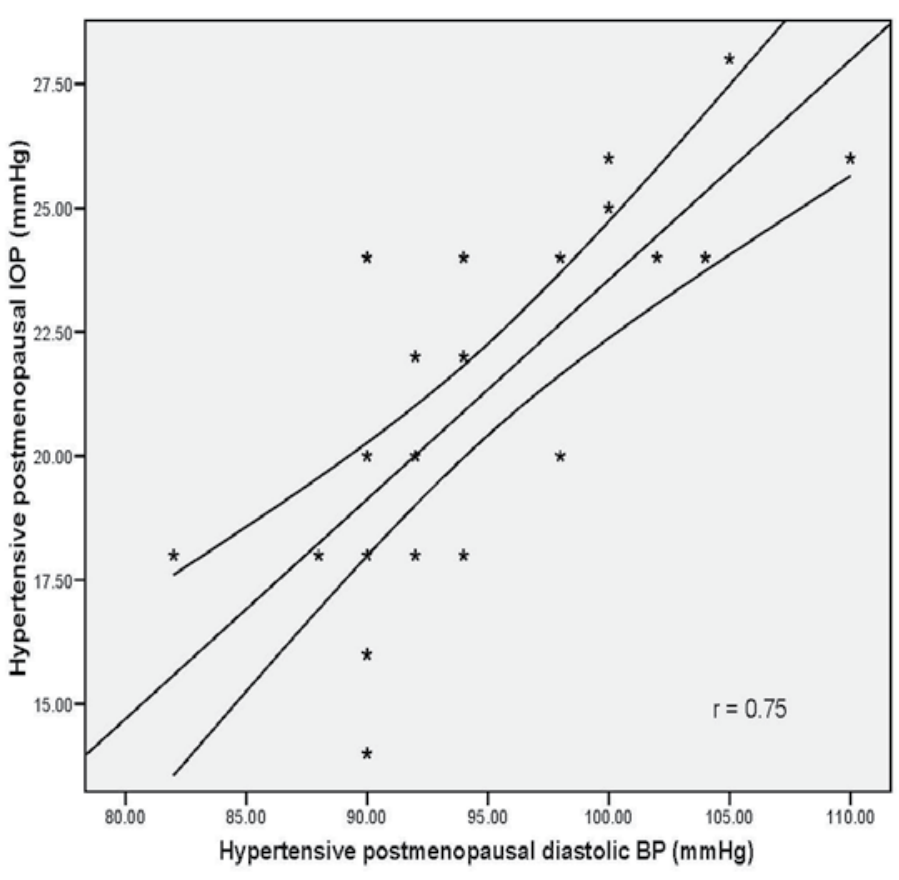

Figure 4: Positive correlation of IOP and diastolic blood pressure in hypertensive postmenopausal women.

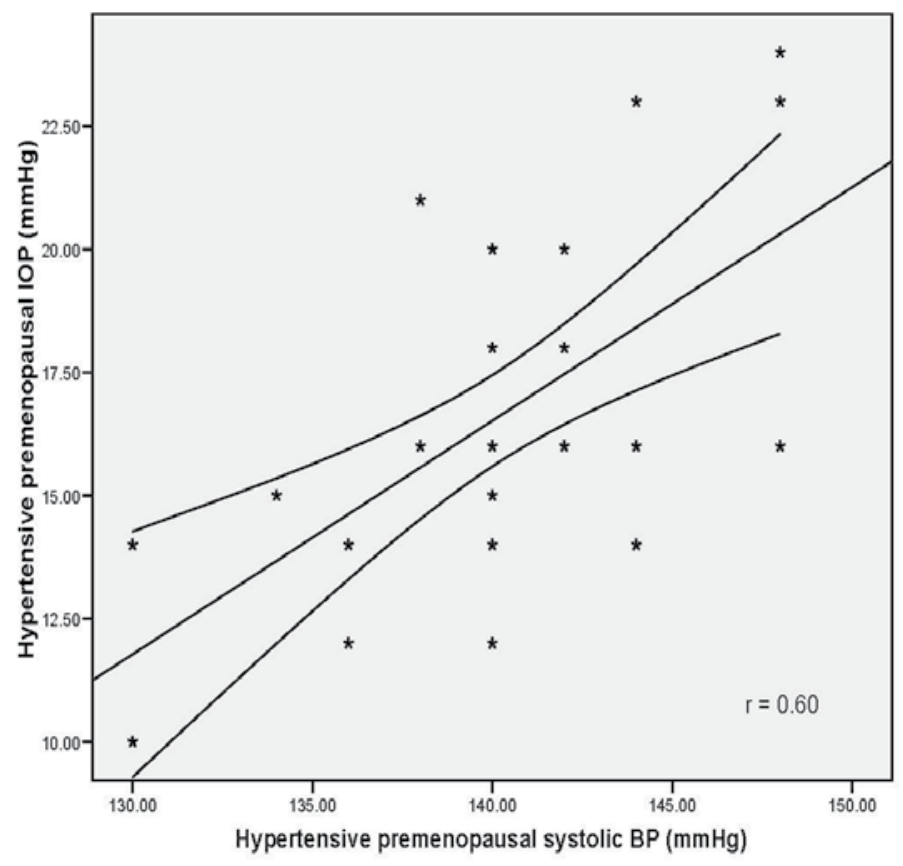

Figure 5: Positive correlation of IOP and systolic blood pressure in hypertensive premenopausal women

\section{Discussion}

The results of this study showed a statistically significant difference in IOP between premenopausal normotensive and postmenopausal normotensive, $1.57 \pm$
$0.76 \mathrm{mmHg},(p<0.05)$ indicative of the influence of menopause on intraocular pressure. This is consistent with other studies ${ }^{4,5}$. The effect of blood pressure is seen in the mean IOP of hypertensive postmenopausal women being higher than that of normotensive postmenopausal women, $2.09 \pm 2.9 \mathrm{mmHg}$, $(p<0.05)$. This effect is also reflected in the difference in mean IOP between the hypertensive and normotensive premenopausal women, $2.00 \pm 0.67 \mathrm{mmHg},(p<0.05)$. However, the difference in mean IOP between the hypertensive premenopausal and normotensive postmenopausal women, $0.43 \pm 1.43,(p>0.05)$ was not significant. This is in agreement with studies ${ }^{5-7}$.

There was a significant positive correlation between IOP and systemic blood pressure in hypertensive postmenopausal women. Our results also showed a statistically significant positive correlation between systolic blood pressure and IOP in the hypertensive premenopausal women. Although a positive correlation was observed between IOP and systolic blood pressure in the premenopausal normotensive women as well as in the postmenopausal normotensive women, it was not found to be statistically significant. This is consistent with a previous study ${ }^{14}$.

The results reported here are generally consistent with those found in the literature ${ }^{16,17}$ correlating IOP and blood pressure in menopausal women. Higher intraocular and blood pressures were reported in the postmenopausal women group than in the premenopausal women group suggestive of the influence of the decline in female reproductive hormones on elevated IOP and blood pressure. Estrogen is known to have vasodilatory effects in the systemic circulation. Decreased estrogen levels during menopause may therefore complicate or contribute to ocular pathologies as estrogen receptors are found in both retinal and choroidal tissue ${ }^{4,5}$.

Another reason could be age related. In this study, the mean age $(52.30 \pm 1.52)$ of the postmenopausal women was slightly higher than that of the premenopausal women $(51.73 \pm 2.23)$, this might have had some influence on the higher systemic blood pressure recorded in the study. This comes as no surprise, as there is a natural tendency for blood pressure to rise with age due to the reduced elasticity of the arterial system. Women going through menopause often experience a loss of elasticity in the carotid artery, the aorta, and other large arteries. This loss of elasticity 
makes it more difficult for the arterial wall to expand and contract with each heartbeat. Over time, this failure can lead to the enlargement of the heart: the heart muscle itself grows as a result of the difficulty in pumping blood through an inelastic arterial system. This in turn can lead to hypertension and heart disease. Some studies had also suggested that the activation of the renin-angiotensin system increased the risk of menopausal women contracting hypertension ${ }^{16-18}$.

Intraocular pressure has been found to be associated with systemic blood pressure levels in population based studies ${ }^{13}, 14$. The relation appears to be reasonably consistent across the range of values of IOP and both systolic and diastolic blood pressure. It has been postulated that the treatment of hypertension may place the eye at relatively increased risk of visual field deficits because of an imbalance in relation of blood pressure to IOP. This thought has been given credence, in part, because of the clinical dictum that sudden lowering of blood pressure is associated with loss of visual field in some people. It was also suggested that the systolic pressure increases the filtrated fraction of aqueous humour to cause a sustained rise in IOP.

Others ${ }^{16,17}$ reported that an increase in body mass index (BMI) in menopausal women may play a greater role than hormonal changes. Menopause-related hormonal changes can lead to weight gain and make blood pressure more reactive to salt in the diet which in turn, can lead to higher blood pressure. Another factor which may lead to weight gain is a loss of energy, thereby increasing the risk of high blood pressure. Depression is yet another risk factor for hypertension. This afflicts some menopausal women.

Some studies ${ }^{10,11}$ report an increase in alcohol consumption and smoking among menopausal and postmenopausal women, both of which are also known risk factors for high blood pressure, heart disease, and stroke. All of these factors may, of course, work singly or in combination to increase the risk. Exposure to lead and lead poisoning may be responsible for an elevated risk of hypertension as well. Bone loss, which takes place at a much higher rate during and after menopause, releases lead stored in the skeletal system. Lead exposure and lead poisoning have long been known to increase hypertension risks in men. The link between lead exposure and hypertension is strongest among post-menopausal women ${ }^{19,} 20$.
We conclude therefore that menopause may affect intraocular pressure. Intraocular pressure is positively correlated with systemic blood pressure in postmenopausal women. Knowledge of the normal level of intraocular pressure during various stages of female reproductive cycle may help during glaucoma screening.

\section{References}

1. Schulzer M and Drance SM. Intraocular pressure, systemic blood pressure, and age: a correlational study. Br J Ophthalmol 198771 245-249.

2. Siesky BA, Harris A, Patel C, Klaas C L, Harris M, McCranor LJ, Lauer J and Kaplan B. Comparison of visual function and ocular hemodynamics between pre- and postmenopausal women. Eur J Ophthalmol 200818 (2) 320323.

3. Sozonoz S Y. Dependence of the intraocular pressure on the systemic blood pressure. Fiziol Zh Sssr Im Im Sechenov 196551 (5) 585-592.

4. Tan JC, Peters DM., Kaufman PL. Recent developments in understanding the pathophysiology of elevated intraocular pressure. Current Opinion in Ophthalmol 200617 168-174.

5. Toker E, Yenice Ö, Temel A. Influence of Serum Levels of Sex Hormones on Intraocular Pressure in Menopausal Women. J of Glaucoma 200312 (5) 436-440.

6. Twiss JJ, Wegner J, Hunter M., Kelsay M., Rathe-Hart M., Salado W. Perimenopausal symptoms, quality of life, and health behaviors in users and nonusers of hormone therapy. $J$ Am Acad Nurse Practitioners 200719 (11) 602-613.

7. Ümit ÜI, Öztürk F, Hüseyin MT. The effect of menopause on intraocular pressure. Türk Oftalmoloji Dergisi 200110 (4) 211-216.

8. Becker B. The decline in aqueous secretion and outflow facility with age. Am J Ophthalmol 198546 731-736.

9. Bulpitt CJ, Hodes C, Everitt MG. Intraocular pressure and systemic blood pressure in the elderly. Br J Ophthalmol $1975 \mathbf{5 9} 717-720$

10. Carlson KH, McLaren JW, Topper JE, Brubaker RF. Effect of body position on intraocular pressure and aqueous flow. Investig Ophthalmol Vis Sci 198728 1346-1352.

11. Chobanian AV, Bakris GL, Black HR., Cushman WC, Green LA, Izzo JL. Jr, Jones DW, Materson BJ, Oparil S, Wright JT. Jr, Roccella EJ. Seventh report of the Joint National Committee on Prevention, Detection, Evaluation, and Treatment of High Blood Pressure. Hypertension 2003 42 (6) 1206-1252.

12. Jaén-Díaz J, Cordero-García B, López-De-Castro F, DeCastro-Mesa C, Castilla-López-Madridejos F, BercianoMartínez F. Diurnal Variability Of Intraocular Pressure. Arch Soc Esp Oftalmol 200782 675-680.

13. Klein BE, Klein R, Knudtson MD. Intraocular pressure and systemic blood pressure: longitudinal perspective: the Beaver Dam Eye Study. Br J Ophthalmol 200589 (3) 284287.

14. Lee AJ, Mitchell P, Rochtchina E, Healey PR. Female 
reproductive factors and open angle glaucoma: the Blue Mountains Eye Study. Br J Ophthalmol 200387 13241328.

15. Leighton DA and Phillips CI. Systemic blood pressure in open-angle glaucoma, low tension glaucoma, and the normal eye. Br J Ophthalmol 197256 447-453.

16. Leske MC, Podgor M.J. Intraocular pressure, cardiovascular risk variables, and visual field defects. Am J Epidemiol 1983118 280-287.

17. Liang $\mathrm{X}$, Wang $\mathrm{X}$, Wang $\mathrm{Y}$ and Jonas $\mathrm{J} \mathrm{B}$. Intraocular Pressure Correlated with Arterial Blood Pressure: The Beijing Eye Study. Am J Ophthalmol 2007144 (3) 461-462.

18. Lu D, Liu X and Wang C. Analysis of intraocular pressure, cup disc ratio and systemic blood pressure for the prediction of prognosis in glaucoma patients. Eye Science 1985 $177-80$.

19. Onakoya AO, Ajuluchukwu JN and Alimi HI. Primary Open Angle Glaucoma and Intraocular Pressure in Patients with Systemic Hypertension. East Afr Med J 200986 224227.

20. Qureshi IA. Intraocular pressure: association with menstrual cycle, pregnancy and menopause in apparently healthy women. Chin J Physiol 199538 (4) 229-234. 